2 Bystrom J, Patel SY, Amin K, Bishop-Bailey D. Dissecting the role of eosinophil cationic protein in upper airway disease. Curr Opin Allergy Clin Immunol 2012;12:18-23.

3 Ozen S, Ruperto N, Dillon MJ, Bagga A, Barron K, Davin JC, et al. EULAR/PReS endorsed consensus criteria for the classification of childhood vasculitides. Ann Rheum Dis 2006;65:936-941.

4 Namgoong MK, Lim BK, Kim JS. Eosinophil cationic protein in Heonoch-Schönlein purpura and IgA nephropathy. Pediatr Nephrol 1997;11:703-706.

5 Kawasaki Y, Hosoya M, Suzuki H. Possible pathologenic role of interleukin-5 and eosino cationic protein in Henoch-Schönlein purpura nephritis. Pediatr Int 2005;47:512-517.

doi: 10.1007/s12519-014-0462-4

\section{Neonatal heart murmur: Is it useful for the diagnosis of congenital heart diseases?}

Oongenital heart disease (CHD) is one of the commonest congenital malformations, affecting 7-8 per 1000 live births, which are mostly asymptomatic at birth. ${ }^{[1]}$ The prevalence of cardiac murmur varies from $0.6 \%$ to $47.4 \%$ and is dependent on sample size, auscultator conditions and skills of the examiner. ${ }^{[1-3]}$ However, not all neonates with CHD are found to have a murmur at postnatal check, and those with murmurs will not have CHD. Wu et a ${ }^{[3]}$ reported that if a murmur is heard, there is an incidence of $42.5 \%$ for cardiac malformations. In contrast, Du et $\mathrm{al}^{[4]}$ mentioned that heart murmur in $84 \%$ of neonates was caused by heart diseases and only $16 \%$ were innocent with a diagnosis of heart disease confirmed by echocardiography. Moreover, Karatza et $\mathrm{a}^{[5]}$ found that auscultation alone has a limited ability to distinguish a pathologic from innocent murmur.

We determined the clinical significance of heart murmur heard during the examination of 2869 neonates from April 1, 2012 to April 31, 2013. Each neonate was thoroughly examined by a pediatric resident. If a murmur was detected, it was reconfirmed by a pediatric consultant. All neonates with murmurs underwent echocardiography. The murmurs were detected in 76 neonates, of whom 37 had a cardiac malformation. The incidence of murmur was 26.49 per 1000 normal neonates. Of the 76 neonates with a murmur, $37 \mathrm{had}$ a significant structural heart lesion (SHL), 16 had an insignificant SHL, i.e., physiological variant, and 23 had a normal echocardiograhic examination (Table). The incidence of CHD was 12.89 per 1000 during the study period. Although SHL was detected in the 37 neonates, 30 had a single SHL and 7 multiple SHL. Patent
Table. Distribution of various causes of heart murmur in neonates

\begin{tabular}{lrr}
\hline Results of echocardiography & Number Percentage, \% \\
\hline Significant cardiac lesions & 12 & 15.79 \\
Patent ductus arteriosus & 9 & 11.84 \\
Ventricular septal defect & 5 & 6.58 \\
Atrial septal defect & 4 & 5.26 \\
Pulmonary stenosis & 3 & 3.95 \\
Transposition of the great arteries & 1 & 1.32 \\
Tetralogy of Fallot & 1 & 1.32 \\
Transposition of great vessels & 1 & 1.32 \\
Tricuspid atresia & 1 & 1.32 \\
Bicuspid aortic valve & \\
Insignificant cardiac lesions (physiological variants) & \\
Patent foramen ovale & 9 & 11.84 \\
Tiny patent ductus arteriosus & 5 & 6.58 \\
Mild peripheral pulmonary stenosis & 2 & 2.63 \\
Normal & 23 & 30.26 \\
Total & 76 & 100
\end{tabular}

ductus arteriosus was the most common SHL (65.63\%) followed by ventricular septal defect, atrial septal defect and pulmonary stenosis. We concluded that if a murmur is heard, there is an incidence of $48.68 \%$ for cardiac malformation. Therefore, murmur should be promptly detected by echocardiography. Although the presence or absence of heart diseases could be determined in most neonates, the lesion-specific diagnosis is not satisfactory. Echocardiography is necessary for neonates with a clinically diagnosis of heart disease.

\section{Amar Taksande \\ Jawaharlal Nehru Medical College, Sawangi Meghe, Wardha Maharashtra -442 004, India \\ Email: amar.taksande@gmail.com}

\section{References}

1 Ainsworth S, Wyllie JP, Wren C. Prevalence and clinical significance of cardiac murmurs in neonates. Arch Dis Child Fetal Neonatal Ed 1999;80:F43-45.

2 Biancaniello T. Innocent murmurs. Circulation 2005;111:e2022.

3 Wu MH, Chen HC, Lu CW, Wang JK, Huang SC, Huang SK. Prevalence of congenital heart disease at live birth in Taiwan. J Pediatr 2010;156:782-785.

4 Du ZD, Roguin N, Barak M. Clinical and echocardiographic evaluation of neonates with heart murmurs. Acta Paediatr 1997;86:752-756.

5 Karatza AA, Fouzas S, Tzifas S, Mermiga A, Dimitriou G, Mantagos S. Accuracy of cardiac auscultation in asymptomatic neonates with heart murmurs: comparison between pediatric trainees and neonatologists. Pediatr Cardiol 2011;32:473-477.

doi: 10.1007/s12519-014-0463-3 